\title{
Erratum to: Preface to Special Issue on User Modelling to Support Personalization in Enhanced Educational Settings
}

Olga C. Santos ${ }^{1} \cdot$ Milos Kravcik $^{1,2}$. Jesus G. Boticario ${ }^{1}$

Published online: 28 June 2016

(C) International Artificial Intelligence in Education Society 2016

\section{Erratum to: Int J Artif Intell Educ DOI 10.1007/s40593-016-0114-z}

The published article lists an incorrect affiliation for the second author (Milos Kravcik). The correct affiliation is "RWTH Aachen University, Aachen, Germany" as shown in this erratum. 